\title{
The Study on Mobile Teaching of Taekwondo in Colleges and Universities Under the Background of "Internet +"
}

\author{
Xiuying $\mathrm{Hu}^{1} \&$ Guanjun Wang ${ }^{1}$ \\ ${ }^{1}$ College of Physical Education, Qingdao University of Science and Technology, Qingdao, Shandong, China \\ Correspondence: Xiuying Hu, College of Physical Education, Qingdao University of Science and Technology, \\ Zhengzhou Road No. 53, Qingdao, Shandong, China. E-mail: 422843222@qq.com
}

Received: April 19, 2018

Accepted: May 2, 2018

Online Published: May 28, 2018

doi:10.5539/ass.v14n6p91

URL: https://doi.org/10.5539/ass.v14n6p91

In this paper, it was the items of teaching reform studies of Qingdao University of Science and Technology, 2018.

\begin{abstract}
We would carry out the important directive spirit of general secretary Xi jin Ping, which was On promoting education informationization. We should vigorously promote the in-depth integration of information technology and university teaching. Only in this way, we could adapt to the current wave of classroom teaching reform in "Internet + teaching".

In this paper, the author has used the methods of document data, expert interview, experiment and comprehensive analysis to research. This paper has studied the new mobile teaching mode of taekwondo course in colleges and universities under the background of " internet +", and has used some various forms of mobile teaching to carry out experimental research.

The results showed that the "dynamic, subtle, video, feedback and evaluation in time" of mobile teaching. It has made the taekwondo students study interest, efficiency, initiative and innovation ability have remarkable improvement, the effect was obviously. It was easy to popularize and popularize.
\end{abstract}

Keywords: The "internet +"; the method of mobile teaching; The colleges and universities; the taekwondo course

\section{Introduction}

Nowadays, the most of college students have all lived in the Internet age, and their social, life, games and shopping were all conducted online. It was also easy for students to fall into the "network trap", who were unable to extricate themselves. Therefore, they have needed the correct guidance from our university teachers, for example, the teachers should renew the teaching philosophy, innovate the teaching mode, and stimulate students' interest in learning. So, new age has needed new requirement, we should take use of the informatization to play the most effective in physical education teaching.

The state council has issued the guideline on actively promoting the "Internet +" action in July 2015.This was the further evolution of the Internet form driven by the innovation of knowledge society. At the same time, it has also promoted the new situation of open innovation and collaborative innovation information society. It has also changed the way people study, live and live, included the improvement and research of physical education methods and means. (Li, 2013)

By the form of moving teaching we have improved college taekwondo teaching concept, means and method, aimed at enhancing the students' interest in learning, improving the quality of teaching, has made students form healthy lifetime sports consciousness under the background of "internet +".

\section{The Research Object}

We have quantized analysis on two groups of students' physical quality and basic skills of taekwondo in order to guarantee the validity of the experiment. Before the start of the experiment, and extracting the same level of two girl students of class nature in 2016 grade of Qingdao University of science and technology to compare the experimental teaching, and these girls were the same of the taekwondo technology. 


\section{The Methods}

\subsection{This Article's Method of Literature Review}

The authors researched the information reform of teaching methods around mobile teaching and college taekwondo courses. We also reviewed the research results of relevant disciplines in and out of China in the past 10 years, researched the data, collected the theoretical support, and laid the foundation. (Shen, 2015)

\subsection{The Method of Interview with Experts and Scholars}

On the topic of research, we has traceability accessed for the experts and scholars who were from Beijing university, Tianjin normal university, Shanghai sports institute, Shandong normal university, Qingdao university of science and technology. We have asked for the research ideas of teaching reform and the indexes of experimental design. And these ideas and indexes were concentrated on the form of mobile teaching, microteaching, mooc, micro lectures and taekwondo teaching. (Gao, 2011)

\subsection{The Questionnaire Survey Method}

On the topic of research, we has designed and issued questionnaires basing on the experts ideas. We issued 15 expert questionnaires, recovered 15, 100 per cent recovery and 100 per cent efficiency. We issued 60 students questionnaires, recovered 60,100 per cent recovery and 100 per cent efficiency.

\subsection{The Method of Experimentation}

According to the project needs, we have designed the experimental measurement, and distributed to the sports teaching field experts, scholars of the mobile teaching, and collected the experimental results and data of the students, and analyzed and concluded the data. (Wang, 2011)

The experimental design:

Each class was 30 people, and the experiment time was from September 2017 to December 2017.The teaching content was of the test content the first semester of the boxing course of college taekwondo. Among them, the control class used the traditional teaching method to teach, while the experimental class adopted the various forms of mobile teaching to conduct experimental teaching. In addition, three teachers were selected to test and evaluate students' quality, special skills, learning attitude, learning interest and learning initiative. (Zhang, 2014)

Among them, the special quality was based on "the college student's test standard table" to Evaluate, and to check and ratify the quality score of the test according to the standard. For example, 100 meters was $15^{\prime} 80$, it was 100 points. The results in this paper were all averages. Taekwondo specific skill testing was on the basis of Qingdao University of science and technology college students taekwondo evaluation criteria of evaluation, technology assessment by the double blind method, and the article the skills of the chart reflect the skill score was average.

\subsection{Comprehensive Analysis Method}

Focusing on the topic of this paper, we have made a careful comparison and analysis of the collected data. The experimental results were calculated and analyzed by mathematical and comprehensive analysis. The application of teaching in the professional courses of taekwondo was summarized and summarized.

\section{Research Results and Analysis}

\subsection{The Transverse Data Analysis of This Article}

\subsubsection{The Test Results and Analysis of Two Groups Before the Experiment}

From the Figure 1, we have known that there was no significant difference between the two groups. So the experiment could be conducted normally and effectively.

The mean score of 100 meters was 17 " 8 . The 800 meters, the average score of the endurance quality was 3 ' 40 ".

According to the physical monitoring standard of university students in Qingdao University of science and technology, their physical condition level was equal, which guarantees the effective conduct of the experiment. In addition, these girls don't have taekwondo training experience before the experiment, just because they liked the taekwondo or because interested in taekwondo to choose taekwondo course.

So these students' special skills would be very general. This was obvious in Figure 1. For example, the test scores of the two groups of students in front kick, cross kick and comprehensive gait were between 50 and 60 , and the average level was low. But the experimental group and the control group had similar levels. (Mei, 2003)

It could be seen that there was no significant difference between the two groups of students' special skill level of 
taekwondo, which was also guarantied the effective conduct of the experiment. (Cai \& Yang, 2016)

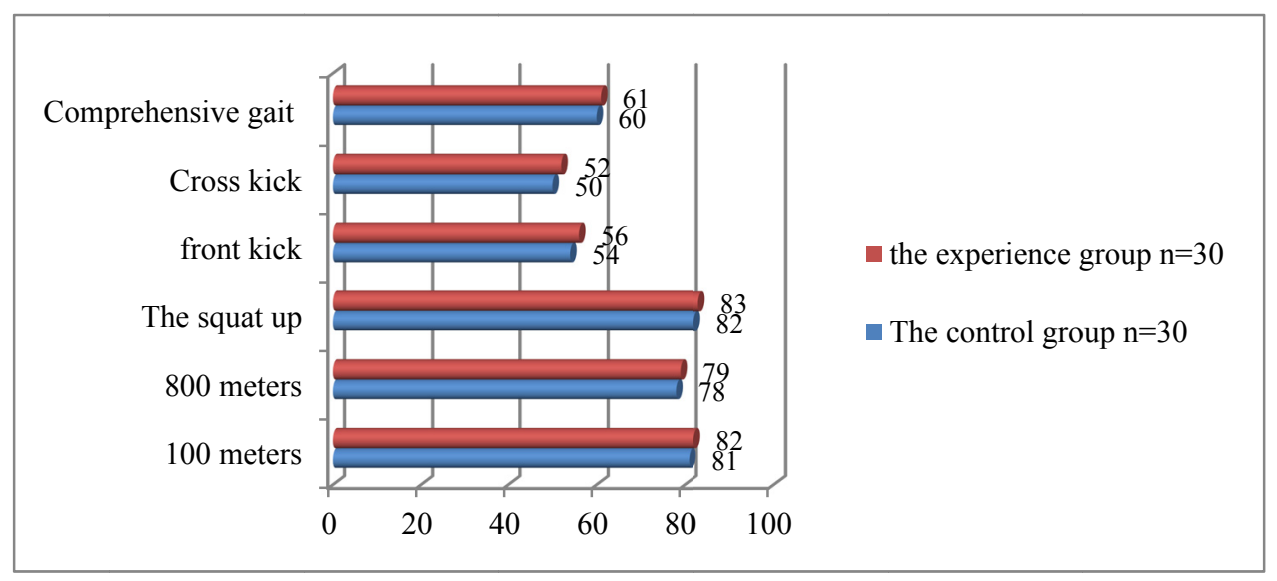

Figure 1. The test data of the two groups before the experiment

Note: The assessment of physical quality and technical skills was 100 point. The assessment was conducted by three professional teachers of taekwondo who don't teach these students. It was according to the college students' physique test standard and the test standard of special skill of taekwondo. The data in the table was the mean.

\subsubsection{The Test Conclusion and Analysis of These Groups After the Experiment}

As you could see from Figure 2, the two classes of students have improved in different degrees, especially the special technical level has been greatly improved through 16 weeks of teaching and training. Analysis reasons:

Firstly, the students Taekwondo technology foundation was basically zero before the students have learned the taekwondo courses. Therefore, the level of special skills has been significantly improved after a semester of specialized courses.



Figure 2. The test data of the two groups after the experiment

Note: The assessment of physical quality and technical skills was 100 point. The assessment was conducted by three professional teachers of taekwondo who don't teach these students. It was according to the college students' physique test standard and the test standard of special skill of taekwondo. The data in the table was the mean.

Secondly, in addition, the students in the experimental class were significantly higher than the control group in the special skills of front kick, cross kick and comprehensive gait, through the infiltration of mobile teaching. There were 9 to 10 points of improvement, and there was a significant difference. This has shown that the special technical level of students has been improved by leaps and bounds, and the teaching quality has improved significantly through the development of the mobile teaching form of taekwondo. (A, 2009)

Comprehensive analysis has shown that there was a significant difference between the experimental class and the control class, and there was a significant difference in the physical quality of the two groups of students. The special skill level had a significant difference, which fully had reflected the effective application and good effect of mobile teaching in taekwondo courses. 


\subsection{The Longitudinal Data Analysis of the Conclusion}

\subsubsection{The Description and Analysis Before and After for the Experimental Group}

Table 1. The comparison table of the experimental group before and after the experiment $(n=30)(G a o, 2011)$

\begin{tabular}{cccc}
\hline Test project & $\begin{array}{c}\text { the experience group before the } \\
\text { experiment }\end{array}$ & $\begin{array}{c}\text { the experience group after the } \\
\text { experiment }\end{array}$ & $\mathrm{P}$ \\
\hline 100 meters & 82 & 87 & $<0.05$ \\
800 meters & 79 & 88 & $<0.01$ \\
The squat up & 83 & 90 & $<0.05$ \\
Front kick & 72 & 83 & $<0.01$ \\
cross kick & 73 & 85 & $<0.01$ \\
Comprehensive gait & 73 & 84 & $<0.01$ \\
\hline
\end{tabular}

Note: The assessment of physical quality and technical skills was 100 point. The assessment was conducted by three professional teachers of taekwondo who don't teach these students. It was according to the college students' physique test standard and the test standard of special skill of taekwondo. The data in the table was the mean.

As could be seen from Figure 1, both the experimental group and the control group had the same level of physical quality and specific skills, before the experiment. According to Figure 1 and Figure 2, there was no significant change in the control group before and after the experiment.

However, the experimental group in the experiment of mobile teaching in taekwondo. The students' learning initiative, participatory enhancement, the form of practice was more novel, and the students' physical quality has been improved unconsciously, through the corresponding changes and adjustments of teachers' roles, students' roles, teaching methods and means, teaching characteristics and environment Settings, etc.

According to Table 1, the score of 100 meters was increased from 82 to 87 before the experiment, and the rapid reaction ability was obvious. The main reason was that the targeted taekwondo rapid reaction ability practice was carried out, and the whole process was tracked, together with the improvement of teaching methods. The learning effect was significantly different in the mobile teaching.

The special endurance was very important for the teaching and training of taekwondo, which has affected the technical level of taekwondo. In mobile teaching, the team has given the students to set up short-term targeted goals, timely communicating with students. The experimental group students' grades have greatly improved, and the overall quality has improved a lot.

The taekwondo was the "art of kicking". So the training of the leg strength and coordination skills was very important.

The leg strength was not simply a practice and test of standing long jump, but a specific training method of taekwondo has madel the students more specific, more motivated and more practical. Through the experiment of mobile teaching, the average score has increased from 83 to 90 .

Analyzing this data, the taekwondo specific physical qualities of students have given full play to the mobile teaching mode in the powerful role of taekwondo classes. Those students were in the experimental group have significant differences by moving the experiment teaching and some data been highly significant difference. The table 1 has shown that the students of special skills was highly significant difference. (Chen \& Wei, 2012)

4.2.2 The Contrast Table of Participation and Innovation Ability of the Experimental Group Before and After the Experiment

We have interspersed with the comprehensive training of taekwondo in mobile teaching. It has let the students study many skills. For example, made the students participate in teaching and curriculum design; participated in the organization and demonstration of the referee's work; participated in the roles of coaches and players. These have made the students' ability of organization, team cooperation ability and the social ability, organization and management ability improve more and more。

As shown in Figure 3, classroom participation increased from 82 to 96 before the experiment, it was highly significant difference.

As shown in Figure 4, the students' innovation ability and team cooperation ability and improvisational strain capacity are greatly improved through the selection and application of techniques and tactics in actual combat games. It is significant difference. 


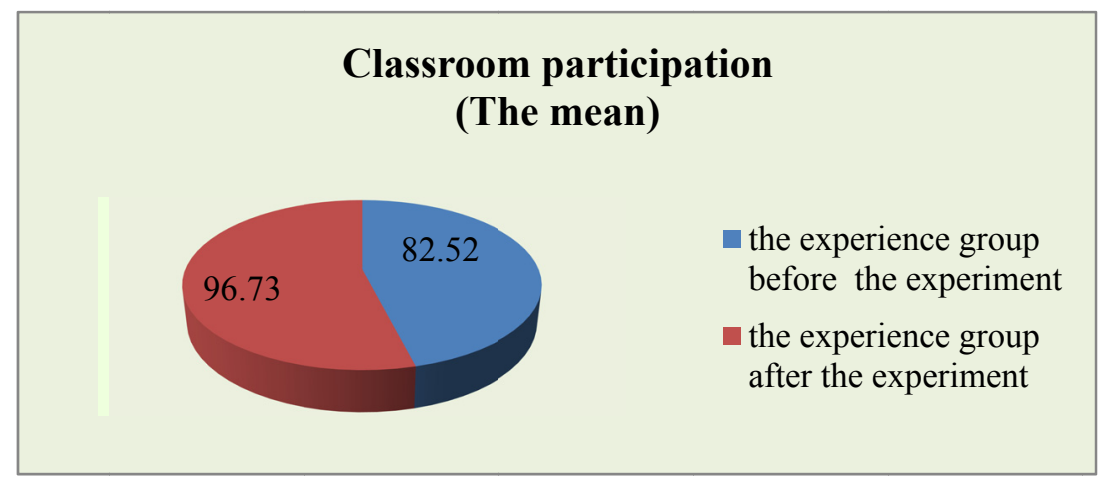

Figure 3. The classroom participation in the experimental group before and after the experiment Note: the same as Figure 1

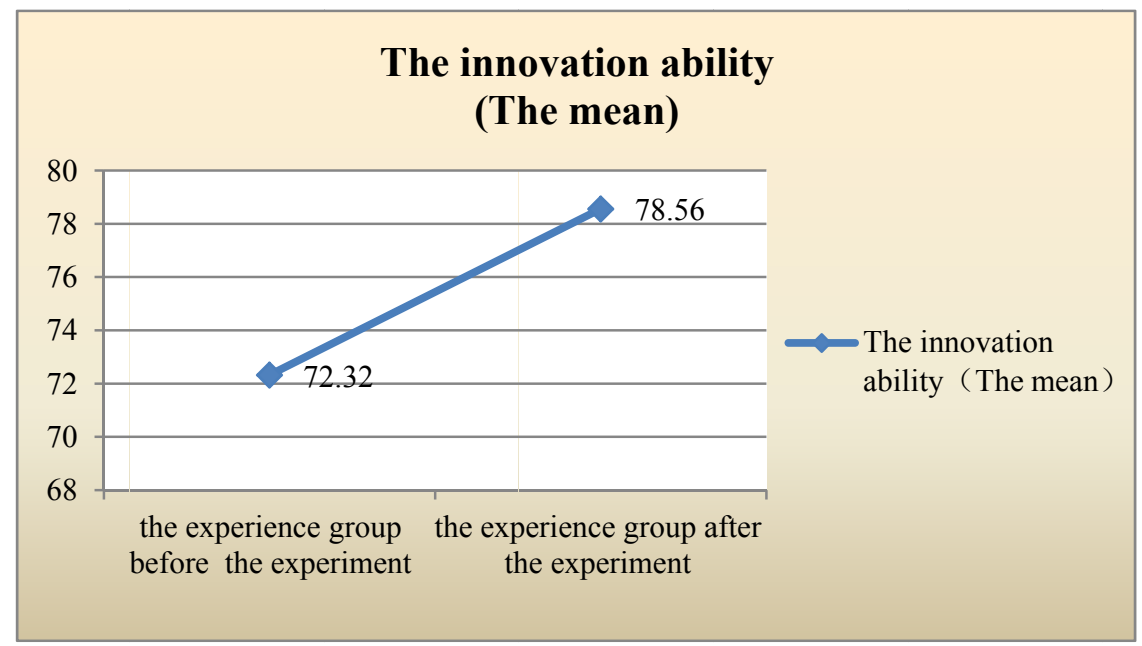

Figure 4. The innovation ability in the experimental group before and after the experiment Note: the same as Figure 1

4.2.3 The Comparison and Analysis Table of the Learning Interest and Teamwork Ability for the Experimental Group

As shown in Figure 5 and 6, the application of mobile teaching has made students willing to participate in taekwondo teaching, so that students' learning interest could been greatly improved in the process of organization, practice, arrangement, etc. At the same time, it was necessary for students to practice tacit understanding through cooperation and cooperation, so as to achieve good results in class. Therefore, the communication and communication between students was closer, and the cohesion was stronger, and the teamwork ability was improved. So the difference was obvious. (Wang, He, \& Zhu, 2013)

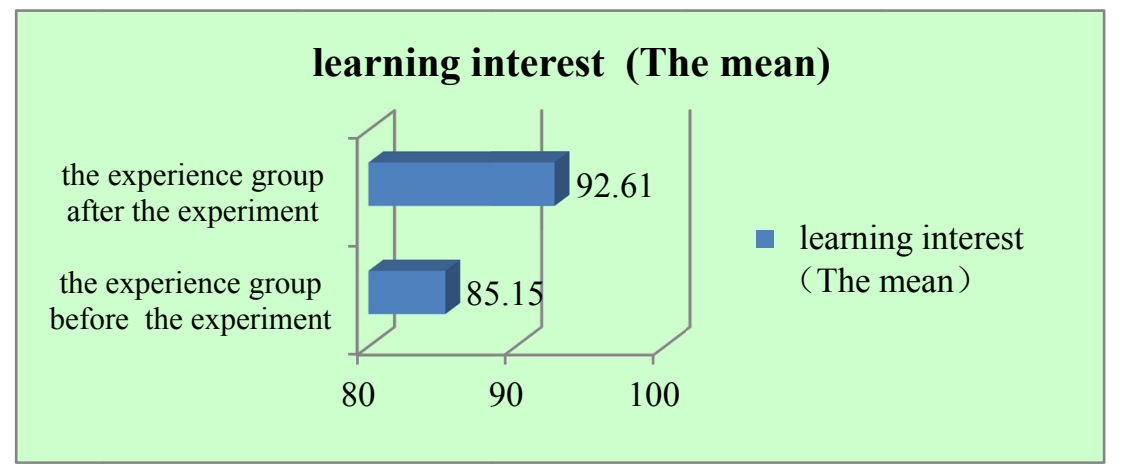

Figure 5. The learning interest of students in the experimental group before and after the experiment

Note: the assessment of physical quality and technical skills was 100 point. The assessment was conducted by three professional teachers of taekwondo who don't teach these students. It was according to the college students' physique test standard and the test standard of special skill of taekwondo. The data in the table was the mean. 


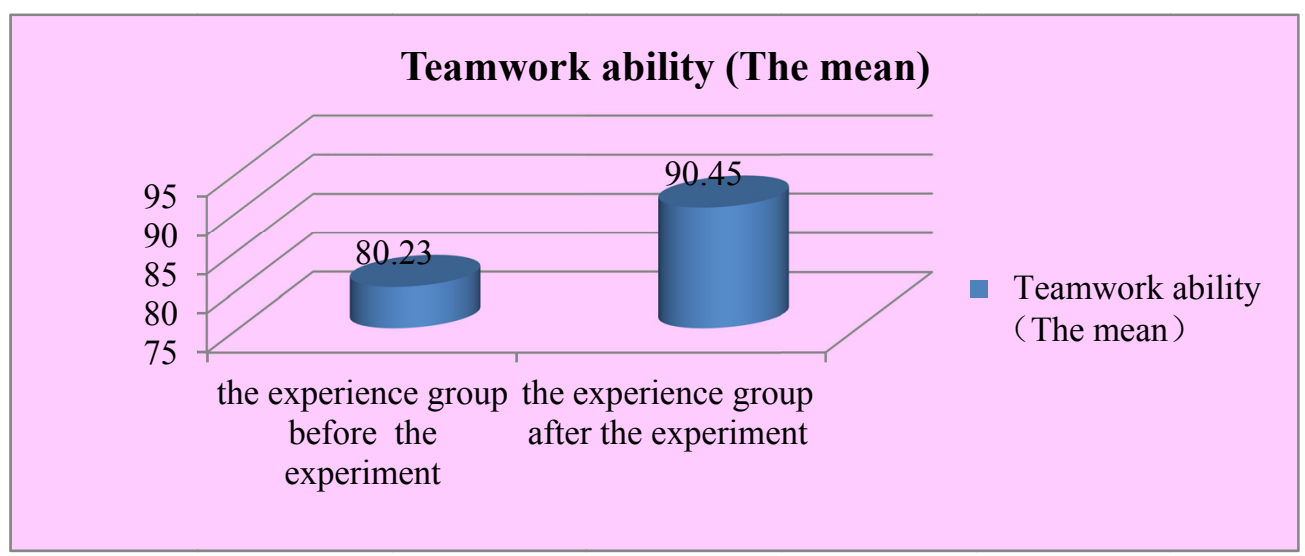

Figure 6. The Teamwork ability in the experimental group before and after the experiment Note: the same as Figure 5

4.2.4 The Contrasting Data of Knowledge of Taekwondo and the Rapport Between the Teacher and the Student for the Experimental Group

As shown in Figure 7 and 8, the students' learning interest, taekwondo knowledge, and the degree of harmony between teachers and students have been greatly improved through discussion, feedback and self-reflection.

Through testing, the students in the experimental group made full use of modern technology information technology. The knowledge reproduction level, memory retention level, analytical ability has significantly higher than the control group. There were significant differences between the experimental group and the experimental group. (Zhang, 2013)

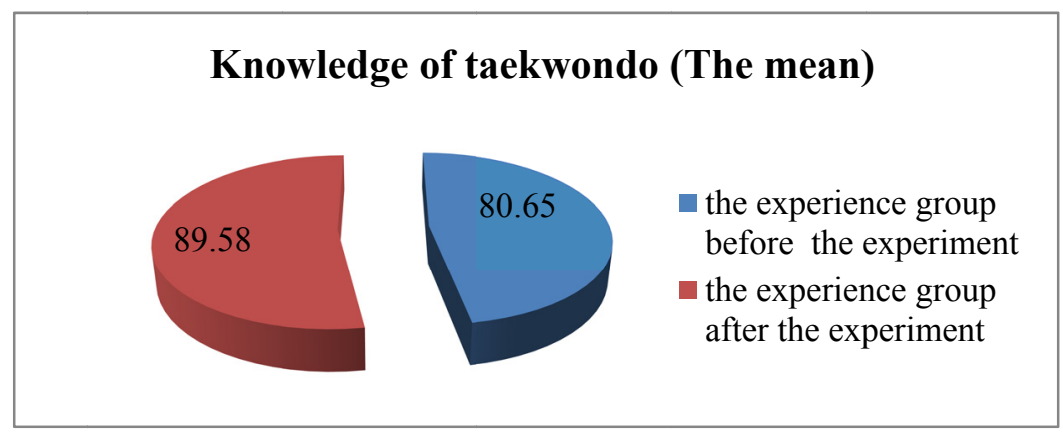

Figure 7. The rapport between the teacher and the student in the experimental group before and after the experiment

Note: the assessment of physical quality and technical skills was 100 point. The assessment was conducted by three professional teachers of taekwondo who don't teach these students. It was according to the college students' physique test standard and the test standard of special skill of taekwondo. The data in the table was the mean.

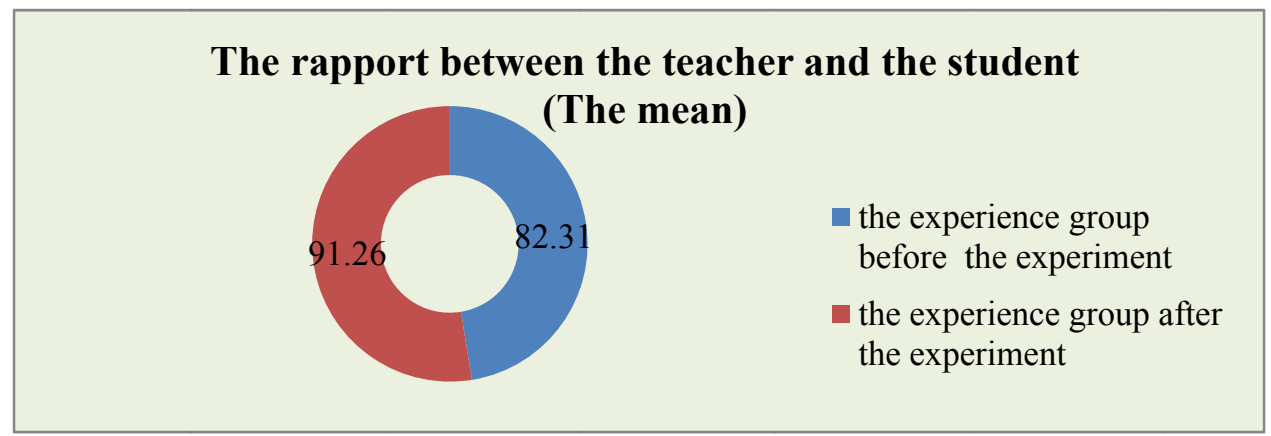

Figure 8. The Knowledge of taekwondo in the experimental group before and after the experiment Note: the same as Figure 1 


\section{Conclusions and Suggestions}

5.1 It has be seen from a semester's experiment, the "dynamic, subtle, video, feedback and evaluation in time" of mobile teaching under the background of "internet +". It has made the taekwondo students study interest, efficiency, initiative and innovation ability have remarkable improvement, the effect was obviously. It was easy to popularize and popularize.

5.2 The "Internet plus" information means and the advanced education concept of the mobile teaching have made the students' reaction ability, tolerance and special forces in the taekwondo courses of ordinary universities significantly improved. At the same time, it has made a qualitative leap in the basic leg and footwork techniques of taekwondo. (Shen, 2017)

5.3 In the mobile teaching of taekwondo in ordinary universities. The students had a polyhedral test through the transformation of the classroom, and the transformation of teaching roles. For example, the students have experienced the role of the organizer and organizing the organization in organizing taekwondo competition. In the referee, the taekwondo law has applied to the sanctions, learned to use. In addition, the teachers had used the video and its cases to show to the students, explained the working methods in the process of competition organization, and shown the mistakes. In this process, these students would experience many unprecedented experiences and gain valuable experience, and their ability would be improved to innovate and explore. (Yang, 2012)

\section{References}

A, Y. G. (2009). The Research of the Network Current Situation Which is National and Provincial Level Sports Courses. The Sports and Science, (11), 11-12.

Cai, R. H., \& Yang, S. Q. (2016). A Case Study of Mobile Learning in Colleges and Universities. Science Tribune, (6), 10-11.

Chen, W. J., \& Wei, M. W. (2012). The Experimental Study on the Application of Microteaching in Taekwondo Teaching. Contemporary Sports Technology, (4), 91-92.

Gao, S. Q., \& H, J. J. (2011). The Overview of the Development of Mobile Learning Applications in Foreign Countries. The Research of Electrochemical education, (5), 108-109.

Gao, Y. (2001). The Basic Skills of Modern Teaching. Shan Dong: Qingdao Ocean University Press, (2), 82-136.

Li, X. (2013). The Research on the Influence Factors of Mobile Learning in New Media Era. The Educational and Technical Equipment of China, (7), 17-18.

Mei, Y. P. (2003). The Analysis and Application on the Application of Sports Game in Basketball Mobile Teaching. The Academic Journal of People's Liberation Army Sports Institute, (1), 116-117.

Shen, T. J. (2015). The Integration of Domestic Mobile Learning and Traditional Learning. Science Tribune, (5), 11-12.

Shen, Z. P. (2007). The Research of Improve the Teaching and Training Quality of Aerobics by Using Microteaching Model. Journal of Beijing Sports University, (12), 1693-1694.

Wang, D. P., \& L, S. N. (2011). The Experimental Study of Microteaching in Table Tennis Ptions in Colleges and Universities. The Notification for General Information of Sports Science and Technology Literature, (2), 27-28.

Wang, M., He, B., \& Zhu.Z. T. (2013). The Micro Video Courses: Evolution, Positioning and Application Fields. The China Educational Technology, (4), 88-94.

Yang, J. F. (2012). The Experimental Research of PE Teaching Skills of Microteaching Training Based on the Case Study. Journal of Guangzhou Sports University, (32), 118-120.

Zhang, L. M. (2014). To Cultivate Students' Autonomous Learning Ability Based on Mooc. The Science Technology Information, (27), 132-133.

Zhang, X. H. (2003). The Experimental Study on the Micro Teaching of Basketball Teaching Technology of Education Students. The Learned Journal of Shanghai Sports Institute, (5), 80-82.

\section{Copyrights}

Copyright for this article is retained by the author(s), with first publication rights granted to the journal.

This is an open-access article distributed under the terms and conditions of the Creative Commons Attribution license (http://creativecommons.org/licenses/by/4.0/). 